\title{
Birth Cohort Differences in Features of Antisocial Alcoholism Among Men and Women
}

\author{
S.F. Stoltenberg, E.M. Hill, S.A. Mudd, F.C. Blow, and R.A. Zucker
}

\begin{abstract}
Background: This study examines the relations between birth cohort, gender, and family history of alcohol problems on alcohol dependence, and on the endorsement of alcohol abuse/dependence symptoms related to antisocial behavior.

Methods: $\operatorname{Mcn}(n=1365)$ and women $(n=625)$ were recruited from the community, hospitals, and other treatment sites and were given a structured diagnostic interview. Data were analyzed by using logistic regression.

Results: Age of first regular alcohol use was lower in more recent birth cohorts for both men and women, with those born in the most recent cohort reporting earliest regular use. The decline across cohort was more dramatic in women than in men. For those participants with a diagnosis of alcohol dependence, being born in a more recent cohort was associated with increased risk of dependence onset before age 25 . Among those participants with onset of alcohol dependence before age $25\left(n_{\text {men }}=400 ; n_{\text {women }}=51\right)$, being born in a more recent cohort was associated with increased risk of fights while drinking, police involvement, and drunk driving trouble as well as with increased risk for a diagnosis of abuse or dependence on another drug.

Conclusions: These results suggest that the prevalence of antisocial alcoholism may be increasing for both men and women. These data exemplify how societal change may affect expression of underlying vulnerability for traits thought to be genetically influenced.
\end{abstract}

Key Words: Early Onset, Age at First Use, Epidemiology, Typology.

$\mathbf{P}$ ATTERNS OF ALCOHOL use and alcohol problems in the United States have changed dramatically in the 20th century (National Institute on Alcohol Abuse and Alcoholism, 1997). Individuals born after Prohibition and after World War II are more likely than individuals born before then to use drugs and alcohol and to become dependent on them (Grant, 1997). Those born more recently are also more likely to begin using alcohol regularly before age 21 (Johnson et al., 1996). In a national survey, younger age was found to be associated with increases in the report of social consequences related to drinking (Midanik and Clark, 1995). Males continue to begin regular alcohol use at an earlier average age than females; however, there is a trend toward a reduction in this difference between males and females (Johnson et al., 1996). Reich et al. (1988) described secular changes in alcoholism that included increased risk for alcoholism, increased transmissibility, and

From the Department of Psychiatry, Alcohol Research Center, University of Michigan, Ann Arbor (S.F.S, S.A.M., F.C.B., R.A.Z.) and the Department of Psychology, University of Detroit Mercy, Detroit, Michigan (E.M.H.).

Received for publication October 9, 1998; accepted September 17, 1999

This work was supported by National Institute on Alcohol Abuse and Alcoholism Grants T32 AA07477, F32 AA05532, R21 AA10696, and R01 AA07065.

Reprint requests: S.F. Stoltenberg, University of Michigan Alcohol Re search Center, Department of Psychiatry, 400 East Eisenhower Parkway, Suite 2A, Ann Arbor, MI 48108-3318; Fax: 734-998-7994; E-mail: sstolten@umich.edu

Copyright 101999 by the Research Society on Alcoholism. decreased age of symptom onset in more recently born than in older cohorts. Reich et al. (1988) also reported that the trends in age of onset were more dramatic in females; specifically, the decrease in modal age of alcoholism onset was greater for women ( $\sim 8$ years) than for men ( $\sim 4$ years) in the younger, relative to the older, cohort.

If age of alcoholism onset is declining more rapidly in women than in men, this may affect one of the most influential alcoholism typologies. Cloninger (1987) called alcoholism with early onset of dependence "male-limited" (i.e., Type II), because it seemed to be rare in women. More recently, however, there have been reports of Type II-like alcoholism in women, with characteristically early onset of symptoms. Lex et al. (1991) reported Type II alcoholism characteristics, such as onset of alcohol problems before age 25 and a family history of alcoholism, in a sample of women incarcerated for driving while intoxicated. Women who had onset of alcohol-related legal problems before age 25 began regular drinking an average of more than 6 years (age 13.5 vs. 20) before those whose drinking problems began after age 25. Glenn and Nixon (1991) reported that in a sample of women in alcoholism treatment, those with onset of symptoms before age 25 resembled male Type II alcoholics in terms of demographic and psychosocial variables, alcohol abuse severity, family history of alcoholism, psychopathological symptoms, and substance abuse history. Early onset of alcohol problems does not seem to be lim- 
ited to males, and the associated behavior patterns seem to be similar in men and women (see Cloninger et al., 1996).

Early onset alcoholism is considered to have a stronger genetic basis than does late onset alcoholism (BuydensBranchey et al., 1989; McGue et al., 1992; van den Bree et al., 1998). Although no gene has been identified convincingly to be associated with vulnerability to early onset alcoholism, it is likely that the serotonergic neurotransmitter system plays a role (see Hill et al., 1999 for a review). Recent studies have not provided easily interpretable results, however. For example, results of a large, family-based study failed to provide evidence of linkage or association of the functional promotor polymorphism in the serotonin transporter gene with alcohol dependence (Edenberg et al., 1998). It may be that multiple components of the serotonergic system (i.e., transporter, receptors, synthetic and metabolic enzymes) will need to be considered to obtain a clearer picture of their influence on alcohol-related traits. A strategy to reduce underlying genetic heterogeneity, narrowing the phenotype (Lander and Schork, 1994; Schork and Schork, 1998), has been used successfully to identify linkage of a serotonin receptor variant (HTR1B G861C) to antisocial alcoholism (AAL) in two populations (Finnish and Southwest Native American; Lappalainen et al., 1998). However, the question of how to best narrow the alcoholism phenotype remains unanswered.

Because early regular alcohol use is associated with Type II-like alcoholism in women (Glenn and Nixon, 1991; Lex et al., 1991) and in men (Irwin et al., 1990), we were interested in whether the trend toward regular alcohol use at a younger age (Grant, 1997; Johnson et al., 1996; Reich et al., 1988) is associated with a similar change in AAL-like behavior patterns. That is, do those in more recent birth cohorts exhibit an increased frequency of antisocial behavior that is associated with earlier initiation of regular drinking?

In the present study, we examined gender, family history of alcohol problems, and cohort differences in AAL-like alcohol abuse/dependence symptoms [not antisocial personality disorder (ASPD) diagnosis] in a heterogeneous sample of participants in research studies at the University of Michigan Alcohol Research Center (UMARC). We hypothesized that a greater proportion of those in the more recent birth cohorts would endorse alcohol abuse/dependence symptoms related to the AAL type. Because of societal changes that are permissive of women drinking in public and because of the rapid decrease in age of regular drinking onset in women, we expected that any increase in symptom endorsement would be greater in women than in men. Also, based on the findings of Reich et al. (1988), that the transmissibility of alcoholism is greater in younger than in older cohorts, we expected to find cohort by family history of alcohol problem (FHA) interactions, such that those in more recent birth cohorts with high levels of FHA are at elevated risk for early onset of alcohol dependence.

\section{METHODS}

\section{Participants}

General recruitment and screening procedures at UMARC were described previously (Hill et al., 1994, 1997). Participants $(n=1990)$ were recruited from alcoholism treatment centers, hospitals, and family practices and from the general population through advertising, direct mailings, and word-of-mouth. After a brief screening interview, those who consented and were eligible for further studies were given the structured diagnostic interview analyzed herein. Patients from alcohol treatment centers were initially screened via chart review, which generally excluded subjects known to have Axis I psychiatric disorders that required treatment with medication, such as schizophrenia or manic depression. Occupational socioeconomic status (i.e., occupational prestige from 0 to 100) ratings were based on a revised Duncan's index for census occupational categories (Stevens and Featherman, 1981).

In terms of demographic characteristics, the participants in the UMARC database are representative of residents of southeastern Michigan (Hill et al., 1994). Men are somewhat overrepresented in the database $(68.6 \%)$ due to the increased prevalence of alcoholism in men, which facilitates recruitment from treatment settings, which, in turn, necessitates increased recruitment of men from the community as control subjects. Recruitment source differed by gender $\left(\chi^{2}, 2 d f, p=0.001\right)$ with a higher percentage of men $(38.00 \%)$ recruited from treatment sources than women $(18.44 \%)$ and a higher percentage of women $(67.20 \%)$ recruited from the community than men $(43.16 \%)$. Similar percentages of men $(18.84 \%)$ and women $(14.36 \%)$ were recruited from the other major sources (e.g., family practices and hospitals).

\section{Definitions and Diagnoses}

For the analysis conducted with the entire sample (i.e., both alcoholics and nonalcoholics) to examine influences on age of first regular alcohol use, potential selection bias due to recruitment source was controlled by including the variable $T X$ : community $=0$, other (e.g., hospitals) $=1$, treatment facilities (inpatient or outpatient) $=2$. The sample was subdivided, approximately into thirds, according to Birth Cohort: (0) those born before 1930 [Old]; (1) those born between 1930 and 1949 [Middle]; (2) those born after 1949 [Young]. Because the UMARC has focused research on issues related to aging and alcohol use, individuals born in the 1960 s and 1970 s are underrepresented in the database.

The Diagnostic Interview Schedule (DIS III-R; Robins et al., 1981) was administered to all participants. DSM-III-R alcohol dependence diagnosis was dichotomized such that $0=$ no diagnosis of dependence and $1=$ diagnosis of mild, moderate, and severe dependence. Age of first regular alcohol use was determined by self-report to the DIS III-R item "How old were you when you first had any wine, beer, or other alcohol at least once a month (for 6 months or more)?" Age of alcoholism onset was determined by reported age of onset of the third alcohol abuse or dependence symptom, if the individual ever met criteria for DSM-III-R diagnosis of alcohol dependence (Schuckit et al., 1995).

Responses to five questions ( $0=$ no, $1=$ yes) in the DIS Alcoholism Module were analyzed to represent Antisocial Alcoholism Features (AALF; Cloninger, 1987; Gilligan et al., 1988; Zucker et al., 1996). Variables included fights while drinking ([FWD] "Did you ever get into fights while drinking?"), police involvement ([PI] "Have the police stopped or arrested you or taken you to a treatment center because of drinking?"), drunk driving trouble ([DDT] "Have you ever had trouble driving because of drinking-like having an accident or being arrested for drunk driving?"), accidental injury ([AI] "Have you ever accidentally injured yourself when you had been drinking, for example, had a bad fall or cut yourself badly?"), and risky behavior ([RB] "Have you several times been high from drinking in a situation where it increased your chances of getting hurt-for instance, when driving a car or boat, using knives, machinery, or guns, crossing against the traffic, climbing or swimming?"). The number of endorsements $(0-5)$ of these AALFs was also analyzed. We dichotomized the presence of any other drug abuse/dependence diagnoses (ODAD) 
where $0=$ no abuse or dependence and $1=$ presence of any abuse or dependence diagnosis (other than nicotine and alcohol). For this study, diagnoses of antisocial alcoholism (i.e., requiring ASPD diagnosis) were not made, but DSM-III-R symptoms of alcohol abuse and/or dependence were examined in those who met criteria for alcohol dependence before age 25. We did not assess ASPD in this sample because the ASPD section of the DIS was not administered to approximately one third of the subjects, most of who were in the older cohorts, which would be confounded with a cohort effect. This strategy allowed us to ascertain whether patterns of endorsing these AAL-like symptoms varied across cohort, without being restricted to only those participants who met criteria for ASPD, thereby increasing the sensitivity of our analysis to identify pattern change. We restricted our analyses to symptoms of alcohol abuse or dependence that can be thought of as reflecting impulsive/aggressive acts (fights while drinking, accidental injury, and risky behaviors) and brushes with the law (police involvement and drunk driving trouble). Cloninger's definition of Type II alcoholism includes fighting and arrests associated with drinking (Cloninger et al., 1996). Additionally, personality traits such as high novelty seeking and low harm avoidance are associated with Type 11 alcoholism. It is likely that someone with such characteristics would increase his or her chances for accidental injury, would participate in risky behavior, and would have experienced drunk driving trouble.

Because measures of FHA that provide information on family history density are generally better than dichotomous measures at predicting diagnostically important alcohol use variables (Stoltenberg et al., 1998), we chose the variable "Degree." Degree is a four-level variable indicating either no alcoholic first- (parents/siblings) or second- (aunts/uncles/grandparents) degree relatives $=0$, only second-degree alcoholic relatives $=1$, only first-degree alcoholic relatives $=2$, or both first- and second-degree alcoholic relatives $=3$. Thus, increasing Degree scores indicate greater levels of FHA. Family history of alcoholism was assessed during interviews with participants. Before 1995 a pedigree was constructed, showing children, parents, siblings, aunts, uncles, and grandparents (1441 of 1990 subjects [72.4\%] completed this assessment). Each relative was assigned a level of alcohol use-abstinent, social drinker, and probable or definite alcoholism. Alcoholism was coded using the criteria from the Family Informant Schedule and Criteria (FISC; Mannuzza et al., 1985). When the respondent could give examples of the relative being frequently drunk, drinking regularly and heavily, or "always had a glass in his/her hand," the relative was coded "probable alcoholic." If the respondent could also name specific consequences from the FISC list (legal, marital, work, or health problems, fights when drunk, or alcoholism treatment), that relative was coded "definite alcoholic." In the present analysis "probable" and "definite" codes were collapsed. In 1995 the FH assessment was changed to the screening portion of the Family History Assessment Module (FHAM [Rice et al., 1995]; 539 of 1990 subjects [27.1\%] completed this assessment). Participants were asked about problem drinking by their relatives (mother, father, brothers, sisters, sons, daughters, half-siblings, maternal grandparents, paternal grandparents, maternal siblings, and paternal siblings) with the question: "Has drinking ever caused any of your relatives to have problems with health, family, their job, or the police?" For each relative a yes was coded as "probable" alcoholic and a no response was coded as "not alcoholic."

\section{Statisical Analyses}

The analysis strategy consisted of three stages: First, age of first regular alcohol use was studied in the full sample, including those both with and without a diagnosis of alcohol dependence. Second, age of dependence onset (before or after age 25) was examined in those participants with a diagnosis of alcohol dependence. Third, features of AAL and diagnoses of other drug abuse or dependence were examined in those participants who reported onset of alcohol dependence before age 25 .

Age at first regular use of alcohol was analyzed using multiple regression. Outcome measures that consisted of dichotomous symptom endorsements (yes/no) or counts of symptoms were analyzed using logistic regression. Dummy variables were created for the multilevel variables Degree and Cohort to facilitate interpretation of the odds ratios that result from logistic regressions. In the logistic regression results, the odds ratios estimated for the main effects of following variables (Degdum1, Degdum2, Degdum 3 [for Degree] and Codum1 and Codum2 [for Cohort]) can be interpreted in comparison to Degree $=0$ [for Degree] and Cohort $=$ 0 [for Cohort], respectively. Each model included the predictor variables: Gender, Degdum1, Degdum2, Degdum3, Codum1, Codum2, and interaction terms for Gender $\times$ Degree, Gender $\times$ Cohort, Degree $\times$ Cohort, Gender $\times$ Degree $\times$ Cohort.

\section{RESULTS}

\section{Demographic Characteristics}

The demographic characteristics of the full $(n=1990)$ sample and the subsample of those with onset of alcohol dependence before age $25(n=451)$ are presented in Table 1 .

\section{Age of Regular Alcohol Use Onset}

Multiple regression on age of regular alcohol use onset in the full sample showed that average age of regular alcohol use onset was lower in men (mean $=18.34, \mathrm{SD}=5.57$ ) than in women $($ mean $=22.27, \mathrm{SD}=9.40)[F(1,1597)=$ $98.46, p<0.0001]$. Average age of regular alcohol use onset also differed across birth cohort, from a high of 22.09 $(\mathrm{SD}=10.05)$ in the oldest cohort, to $19.26(\mathrm{SD}=5.55)$ in the middle cohort, to $17.17(\mathrm{SD}=3.52)$ in the youngest cohort $[F(1,1180)=20.04, p<0.0001]$. Average age (mean $\pm \mathrm{SD}$ ) of regular use onset for those in Degree categories 1 (only second-degree relatives with alcoholism, $19.81 \pm 7.68$ ) and 2 (only first degree, $19.00 \pm 6.78$ ) were not significantly different from those in Degree category 0 (no family history, $20.75 \pm 7.79$ ). However, the mean age at regular use onset of those reporting both first- and seconddegree relatives with alcoholism (Degree 3, $17.67 \pm 5.16$ ) was significantly lower than the mean for those reporting no family history of alcoholism $[F(1,1597)=33.63, p=$ $0.0001]$. The interaction between Gender and Cohort was also significant $[F(1,1597)=40.02, p=0.0001]$, indicating that the decrease in age of first regular alcohol use was greater among women than among men. Average ages ( \pm SD) for first regular use for the old, middle, and young cohort, respectively, were as follows: men-19.82 $( \pm 7.74)$, 18.48 ( \pm 4.52$), 16.64( \pm 3.37)$; women-26.47 ( \pm 12.34$)$, $21.97( \pm 7.62), 18.20( \pm 3.59)$. The interaction between family history and cohort was also significant $[F(1,1597)=4.37$, $p=0.04$ ] such that the effect of family history was strongest in the oldest cohort.

\section{Early Onset Alcoholism}

In a second set of analyses, we used logistic regression to examine the dichotomous variable representing alcohol dependence onset before age 25 (1) or after age $25(0)$. Male gender [odds ratio $(\mathrm{OR})=3.72, p=0.0001$ ], having a second-degree relative $(\mathrm{OR}=1.71, p=0.01)$ or first- and second-degree relatives $(\mathrm{OR}=1.71, p=0.01)$ with alcoholism, and being born in the middle $(\mathrm{OR}=1.83, p=$ 
Table 1. Demographic Characteristics of (a) the Full Sample and (b) the Subsample of Those With Onset of Alcohol Dependence Before Age 25

\begin{tabular}{|c|c|c|c|c|c|c|}
\hline \multirow{2}{*}{$\frac{\text { (a) }}{\text { Birth Year }}$} & \multicolumn{6}{|c|}{ Full Sample } \\
\hline & $n$ & Before 1930 & $n$ & $1930-1949$ & $N$ & After 1949 \\
\hline$\%$ Male & 645 & 64.50 & 723 & 76.07 & 622 & 64.15 \\
\hline$\%$ White & 593 & 89.38 & 707 & 82.89 & 612 & 83.50 \\
\hline$\%$ Alcoholic $^{a}$ & 644 & 47.98 & 721 & 57.28 & 604 & 50.33 \\
\hline $\mathrm{Age}^{\mathrm{b}}$ & 645 & $69.72(5.62)$ & 723 & $54.23(6.90)$ & 622 & $32.33(6.75)$ \\
\hline Years of education ${ }^{b}$ & 644 & $13.60(2.90)$ & 722 & $13.89(2.62)$ & 620 & $14.42(2.05)$ \\
\hline
\end{tabular}

a DSM-III-R diagnosis of mild, moderate, or severe alcohol dependence; ${ }^{\mathrm{b}}$ Mean (standard deviation); ${ }^{\mathrm{c}}$ Socioeconomic status indexed by a measure of occupational status.

\begin{tabular}{llllccc}
\hline (b) & \multicolumn{5}{c}{ Early onset } \\
\hline Birth Year & $n$ & Before 1930 & $n$ & $1930-1949$ & After 1949 \\
\hline \%ale & 67 & 92.54 & 153 & 96.73 & 82.25 & 231 \\
\% White & 62 & 88.71 & 152 & 80.26 & 226 & 84.51 \\
\% Never married & 66 & 3.03 & 153 & 4.58 & 231 & 41.99 \\
Age $^{\text {a }}$ & 67 & $66.36(4.36)$ & 153 & $51.48(7.06)$ & 231 & $32.64(6.29)$ \\
Years of education $^{\mathrm{a}}$ & 67 & $12.67(2.83)$ & 153 & $12.74(2.54)$ & 229 & $13.25(2.07)$ \\
SES $^{\text {a,b }}$ & 59 & $37.91(20.33)$ & 120 & $31.62(17.61)$ & 176 & $28.79(14.37)$ \\
\hline
\end{tabular}

${ }^{a}$ Mean (standard deviation); ${ }^{b}$ Socioeconomic status indexed by a measure of occupational status.

Note: Sample sizes vary due to missing values for some variables.

$0.0007)$ or young $(\mathrm{OR}=13.42, p=0.0001)$ birth cohort were associated with onset of alcohol dependence before age 25 . No interaction was statistically significant.

\section{Antisocial Alcoholism Features}

Because Cohort was associated with onset of alcohol dependence before age 25, we further examined cohort effects on AALF in that group to identify specific features that may differ across birth cohort. First, we tested the effects of Gender, Degree, Cohort, and their interactions on a variable representing the number of AALF endorsed, out of five symptoms (fights while drinking, police involvement, drunk driving trouble, risky behavior, and accidental injury). Unless otherwise indicated, inclusion of interaction terms did not increase model fit; therefore we present only main effect models. Male gender $(\mathrm{OR}=2.94, p=0.0001)$, having first- and second-degree relatives with alcohol problems $(\mathrm{OR}=1.81, p=0.02)$, and being born in later cohorts $(\mathrm{OR}=2.19, p=0.003$, and $\mathrm{OR}=2.56, p=0.0002$ for the middle and younger cohorts, respectively) were associated with endorsing greater numbers of AALF.

We then tested each of the five AALF individually to assess whether probability of endorsing these symptoms is different across birth cohorts (see Table 2). All predictive models were statistically significant except for risky behavior $(p=0.35)$ and accidental injury $(p=0.10)$. For descriptive purposes, Table 3 presents the percentages of those with onset of alcohol dependence before age 25 who endorsed specific AALFs and who were diagnosed with abuse or dependence on another drug.

Results of the logistic regression indicated that gender did not influence whether the subject reported getting into fights while drinking (FWD, $p=0.56$ ). In addition, those reporting only second-degree relatives (Degdum1, $p=$ 0.74 ) or only first-degree relatives (Degdum2, $p=0.15$ ) with alcohol problems were not at increased risk for reporting FWD relative to those who reported no family history of alcoholism. However, those who had the highest levels of family history of alcohol problems seem to be at increased risk of reporting FWD compared to those without a family history of alcohol problems (Degdum3, OR $=1.75, p=$ $0.05)$. Those born in the middle $(p=0.03)$ and young $(p=$ $0.006)$ cohorts were approximately twice as likely to report FWD than were those born in the oldest cohort.

Men were at increased risk for police involvement (PI; $\mathrm{OR}=4.87, p=0001$ ) as were those who reported both first- and second-degree relatives with alcohol problems $(\mathrm{OR}=1.79, p=0.05)$ and those born into the youngest cohort $(\mathrm{OR}=1.96, p=0.02)$.

Each of the predictor variables was associated with drunk driving trouble (DDT). Men were at increased risk for DDT relative to women $(\mathrm{OR}=3.38, p=0.0002)$. Having any first- or second-degree relatives with alcohol problems essentially doubled the risk for DDT relative to those without a family history (note: for Degdum $2 p=0.07$ ). Similarly, being born in the middle $(p=0.002)$ or young ( $p=$ 0.01 ) cohort more than doubled the risk for DDT relative to those in the oldest cohort.

Logistic regression indicated that gender and lower levels of FHA were not associated with increased risk for other drug abuse/dependence (ODAD). However, a high level of FHA (i.e., Degdum3) was associated with increased risk for ODAD (OR $=2.68, p=0.003)$. Additionally, being born in the middle $(\mathrm{OR}=4.68, p=0.006)$ or young $(\mathrm{OR}=16.78$, $p=0.0001$ ) cohort was associated with increased risk for ODAD. Those with a diagnosis of abuse/dependence on another drug endorsed more AALF $(3.42 \pm 1.34)$, on average, than those without the diagnosis $(2.96 \pm 1.16 ; t=$ $3.80, p=0.0002$ ).

The trend for those in the younger cohorts to endorse 


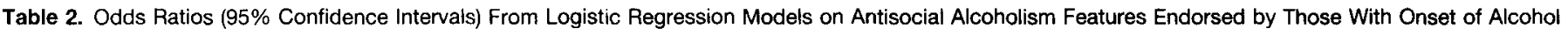
Dependence Before Age 25

\begin{tabular}{|c|c|c|c|c|c|c|}
\hline & Gender & Degree1 & Degree2 & Degree3 & BY $1930-49$ & BY 1949-76 \\
\hline \multirow[t]{2}{*}{ AALSUM } & $2.94^{* \star *}$ & 1.27 & 1.74 & $1.81^{\star}$ & $2.19^{* \pi}$ & $2.56^{\star \star \star \star}$ \\
\hline & $(1.69-5.11)$ & $(0.77-2.09)$ & $(0.99-3.05)$ & $(1.11-2.94)$ & $(1.30-3.69)$ & $(1.55-4.22)$ \\
\hline \multirow[t]{2}{*}{ Fights while drinking } & 1.21 & 0.91 & 1.62 & $1.75^{\star}$ & $1.95^{\star}$ & $2.20^{* *}$ \\
\hline & $(0.64-2.29)$ & $(0.52-1.60)$ & $(0.84-3.10)$ & $(1.00-3.07)$ & $(1.08-3.53)$ & $(1.25-3.88)$ \\
\hline \multirow[t]{2}{*}{ Police involvement } & $4.87^{\star \star *}$ & 1.44 & 1.39 & $1.79^{*}$ & 1.14 & $1.96^{\star}$ \\
\hline & $(2.51-9.47)$ & $(0.80-2.57)$ & $(0.72-2.68)$ & $(1.01-3.18)$ & $(0.63-2.07)$ & $(1.09-3.51)$ \\
\hline \multirow[t]{2}{*}{ Drunk driving trouble } & $3.38^{\star * *}$ & $2.18^{\star}$ & 1.89 & $1.91^{\star}$ & $2.61^{\star \star}$ & $2.15^{\star \star}$ \\
\hline & $(1.79-6.40)$ & $(1.19-3.99)$ & $(0.96-3.72)$ & $(1.08-3.41)$ & $(1.41-4.86)$ & $(1.20-3.83)$ \\
\hline \multirow[t]{2}{*}{ Risky behavior ${ }^{a}$} & 1.39 & 2.03 & 1.01 & 2.95 & 1.46 & 1.25 \\
\hline & $(0.44-4.43)$ & $(0.73-5.66)$ & $(0.37-2.77)$ & $(1.00-8.65)$ & $(0.49-4.31)$ & $(0.45-3.50)$ \\
\hline \multirow[t]{2}{*}{ Accidental injury ${ }^{a}$} & 1.17 & 1.13 & 1.90 & 1.41 & 1.34 & 1.54 \\
\hline & $(0.63-2.18)$ & $(0.65-1.98)$ & $(1.01-3.60)$ & $(0.82-2.43)$ & $(0.75-2.40)$ & $(0.88-2.69)$ \\
\hline \multirow[t]{2}{*}{ Other drug abuse/dependence } & 1.12 & 0.96 & 1.77 & $2.68^{\star \star}$ & $4.68^{\star \star}$ & $16.78^{\star \star \star}$ \\
\hline & $(0.56-2.24)$ & $(0.48-1.89)$ & $(0.84-3.75)$ & $(1.41-5.08)$ & $(1.57-13.97)$ & $(5.80-48.54)$ \\
\hline
\end{tabular}

Note: $N=440$, except risky behavior $N=334$, other drug abuse/dependence $N=423$. Unless otherwise noted $\chi^{2}$ for model $p<0.001 ; \chi^{2}$ for model $p>0.05$; Wald $\chi^{2}$ tests ${ }^{\star} p<0.05,{ }^{\star \star} p<0.01,{ }^{\star \star \star} p<0.001$. BY, birth year.

Table 3. Percentage of Those With Onset of Alcohol Dependence Before Age 25, in Each Category, Who Endorsed the Symptom Fights While Drinking (FWD),

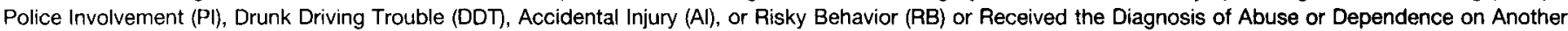
Drug (ODAD)

\begin{tabular}{|c|c|c|c|c|c|c|}
\hline & \multicolumn{6}{|c|}{ Percentage Endorsement } \\
\hline & FWD & PI & DDT & Al & $\mathrm{RB}^{\mathrm{a}}$ & ODAD $^{\mathrm{b}}$ \\
\hline \multicolumn{7}{|l|}{ Gender } \\
\hline Male $(N=399)$ & 61.15 & 66.42 & 70.18 & 50.98 & 86.49 & 37.92 \\
\hline Female $(N=51)$ & 58.82 & 33.33 & 41.18 & 53.13 & 90.49 & 52.08 \\
\hline \multicolumn{7}{|l|}{ Degree } \\
\hline $0(N=83)$ & 54.22 & 55.42 & 56.63 & 45.78 & 86.11 & 27.63 \\
\hline $1(N=124)$ & 52.42 & 63.71 & 72.58 & 49.19 & 92.55 & 27.64 \\
\hline $2(N=76)$ & 65.79 & 61.84 & 68.42 & 61.84 & 85.71 & 40.85 \\
\hline $3(N=157)$ & 68.79 & 68.15 & 69.43 & 55.41 & 94.64 & 54.25 \\
\hline \multicolumn{7}{|l|}{ Cohort } \\
\hline Old $(N=67)$ & 44.78 & 55.22 & 52.24 & 44.78 & 87.76 & 6.90 \\
\hline Middle $(N=152)$ & 61.84 & 59.87 & 73.68 & 51.32 & 90.32 & 25.85 \\
\hline Young $(N=231)$ & 64.94 & 66.67 & 66.67 & 56.28 & 90.53 & 56.58 \\
\hline
\end{tabular}

a Sample sizes for males $=305$, females $=37$; degree $0=72,1=94,2=56,3=112$; cohort old $=49$, middle $=124$, young $=169$

b Sample sizes for males $=385$, females $=48$; degree $0=76,1=123,2=71,3=153$; cohort old $=58$, middle $=147$, young $=228$.

more AALF may reflect a general increase in alcoholism severity that is not specifically related to features of antisocial alcoholism. To test this, we created a variable (ALCSEV) to reflect alcohol problem severity without the contribution of the AALF we analyzed previously. This new variable was constructed by subtracting the number of AALF from the total number of alcohol abuse/dependence symptoms. We then regressed gender, degree, and cohort on ALCSEV for those with onset of alcohol dependence before age 25 . The regression model was not significant $[F(3,355)=1.10, p=0.35]$, indicating that none of the regressors had a significant effect on ALCSEV. Therefore, the cohort effects that we reported earlier do not seem to reflect a general elevation of alcohol problem severity among those born in more recent cohorts.

\section{DISCUSSION}

Individuals in more recent birth cohorts initiate regular alcohol use earlier, are more likely to develop drinking problems before age 25 , and are more likely to endorse features of antisocial alcoholism than are those born in older cohorts. Both birth cohort and high levels of family history of alcohol problems were consistently strong predictors of endorsement of the alcohol abuse/dependence symptoms considered to be features of antisocial alcoholism (AALF). The results of our analyses did not support the hypothesis that the rate of increase of AALF symptom endorsement across birth cohort, in those with onset of alcohol dependence before age 25 , would be more pronounced in women. That is, no Gender $\times$ Cohort interaction was statistically significant.

In our full sample we found evidence that age of first regular alcohol use, among both men and women, was decreasing across birth cohort, with those in the youngest cohort having the earliest regular alcohol use. The change was more pronounced among women than among men, a finding consistent with previous findings (Reich et al., 1988) and suggestive of an increase in problem drinking among women. Heavy drinking by young women may be more common now than in recent decades. Reanalyzing survey data from the United States, Fillmore (1984) found 
that the frequency of heavy drinking (five or more drinks nearly every day) for women in their 20 s increased during the years 1964 to 1979. An analysis of several large national surveys revealed that female cohorts born between 1925 and 1943 showed a higher proportion of heavy/frequent drinkers than the cohort born between 1915 and 1924 (Fillmore, 1987).

Among those with a diagnosis of alcohol dependence, being born in a more recent cohort was associated with increased risk of onset of problems before age 25 . This finding is consistent with the increase in the percentage of individuals in more recent birth cohorts who began using alcohol regularly before age 21 (Johnson et al., 1996). Our finding that FHA was related to early onset of alcoholism and to AALF supports previous findings that a dense family history of alcoholism is generally associated with the antisocial alcoholism subtype (Zucker et al., 1996). Significant heritability estimates have been found in male twins with onset of first alcoholism symptom before age 20 but not in such "early onset" female twins (McGue et al., 1992). These findings suggest the genetic influence on early onset alcoholism may differ in men and women. Based on these findings we hypothesized, but did not find, a gender by family history interaction on early onset of alcohol dependence. Our findings can be interpreted either as not supporting the findings of McGue et al. (1992) or as an example of the differences inherent in the results of twin and family history studies.

Among those with onset of alcohol dependence before age 25 , male gender, being born in a more recent cohort, and a high level of family history of alcohol problems were associated with endorsing more features of AAL. Specifically, those AAL features included fights while drinking, police involvement, drunk driving trouble, and the presence of other drug abuse/dependence.

The increased endorsement rates of AALF that we observed in the younger cohorts may not be restricted to those with early onset of alcohol dependence. Such an increase may be more global in scope and may be seen in those with onset of alcohol problems after age 25 or in those without alcohol problems. To address this we conducted logistic regression analyses, as previously reported, on data from participants without an alcohol dependence diagnosis combined with those with later onset of alcohol dependence (age 25 or after). Our results (not shown) indicated that those in the youngest cohort were less likely than those in the older cohorts to endorse symptoms associated with AAL with the exception of fights while drinking (no difference) and other drug abuse or dependence (young three times more likely to endorse). Therefore, our results do not indicate a more general increase in AALF endorsement but point to an increase in AAL-like symptoms in those with early onset of alcohol dependence, which indicates the potential for a rise in the prevalence of antisocial alcoholism.

The study results are limited in generalizability because the sample is not a national community-based sample.
Participants were recruited from both treatment and community sources, with the largest proportion from treatment settings. Even so, the findings are consistent with other reports in the literature. Another limitation is that the interview data were based on self-report and are therefore subject to the biases known to be associated with such data (Hill et al., 1994, 1997). Differences in recall based on age of subjects may also limit the generalization of the results of the present study. An example of such an age-related bias is the tendency of individuals to report increasing age of onset of substance use (including alcohol) with increasing age (e.g., Labouvie et al., 1997). In the present study, such a bias could affect a primary grouping variable (age of alcoholism onset) by decreasing the number of individuals in the older cohorts grouped in the early onset category.

It may be that early onset alcoholism is related to increased mortality, which would remove the most severe early onset alcoholics from the older cohorts. Studies support the hypothesis that individuals with Type II alcoholism have increased mortality rates. In a sample of Swedish alcoholics, Berglund (1988) found that a compulsory treatment group with higher levels of antisociality/criminality had a higher level of mortality than a matched control group. A substantial number of the deaths in the compulsory treatment group were due to accidents, poisoning, or violence. In a 20-year follow-up study, Lewis et al. (1995) found that having either alcoholism alone or alcoholism and antisocial personality was associated with increased mortality for both men and women. Such differential mortality may help to explain some of the cohort differences we observed in the present study.

To assess the effectiveness of the AAL-like alcohol abuse/dependence features on which our analyses were based, we examined their endorsement frequencies in those participants who completed the ASPD section of the DIS. The endorsements patterns were, for the most part, in the expected direction, that is, higher rates of endorsement for those with a diagnosis of ASPD $(n=117)$ than for those without the diagnosis $(n=1176)$ : fights while drinking $79.5 \%$ vs. $19 . \%$, police involvement $71.8 \%$ vs. $22.6 \%$, drunk driving trouble $75.2 \%$ vs. $24.2 \%$, risky behavior $88.5 \%$ vs. $38.0 \%$, accidental injury $57.3 \%$ vs. $22.0 \%$, and other drug abuse or dependence $66.7 \%$ vs. $10.5 \%$. It seems that the AALFs we identified did index behaviors associated with ASPD diagnosis.

Assuming that these cohort effects are robust and replicable, what do our findings say about the prevalence of antisocial alcoholism, the nature of antisocial alcoholism, or alcoholism typologies? Earlier alcohol use is associated with greater risk for the development of alcohol-related problems (Gruber et al., 1996); on those grounds we should expect a rise in the prevalence of such alcohol problems. Because the decrease in age of first regular alcohol use in this sample was greatest in women, it is reasonable to predict a concomitant rise in alcohol use problems in women. Antisocial behavior and alcohol use are linked, 
especially in women (Zucker, 1994). Therefore, using the term "male-limited" to describe the antisocial alcoholism type seems to have lost its applicability.

Are these data relevant in understanding the underlying nature of antisocial alcoholism? It seems that these cohort effects on features of antisocial alcoholism exemplify the ways in which complex phenotypes are influenced by changing environmental conditions. Societal changes seem to have made it possible for the higher prevalence of behaviors that were once strongly discouraged, especially among women. These data show that even for traits thought to be heavily genetically influenced (such as features of antisocial alcoholism), societal change affects expression. These results indicate that behavioral heterogeneity, related to factors unlikely to have a genetic origin, exists in a type of alcoholism thought to be suitable for genetic dissection (Hill et al., 1999). Therefore, such cohort effects should be considered as one of several "population-level complexities" that may potentially obscure relationships between genes and behaviors (see Schork and Schork, 1998, for a review).

When behavioral traits are considered for genetic dissection, the presence of cohort effects may help to identify the best sampling strategy. Penetrance of AAL-like behaviors seems to be greatest in the youngest cohort, which may make recruitment of relatively large samples feasible and provide increased statistical power to detect alleles with moderate to small effect (although phenocopies may also be more likely). Designs that require the participation of parents are clearly best suited for traits with early onset, because younger people are more likely than older people to have two living parents. Therefore, designs requiring parent-proband trios such as the haplotype relative risk method (Terwilliger and Ott, 1992) or the transmission disequilibrium test (Spielman et al., 1993) may be best. Alternatively, because society seems to be becoming more permissive of the expression of AAL-like behaviors in women, it may be that compared to women in more recent birth cohorts, women in the oldest cohort who endorsed AAL-like behaviors have a higher biological vulnerability to AAL. Therefore, women in the older birth cohorts who meet criteria for AAL are excellent candidates for genetic studies. However, such women are unlikely to have two living parents; therefore, study designs requiring sibs, such as discordant sib-pairs (Boehnke and Langefeld, 1998; Risch and Zhang, 1995; Spielman and Ewens, 1998), may best use this cohort.

In conclusion, those born more recently are at greater risk for earlier regular drinking and for developing alcohol dependence before age 25 than are those born earlier. Among those with onset of alcohol dependence before age 25 , those born more recently are at greater risk for fighting while intoxicated, police involvement, drunk driving trouble, and a diagnosis of abuse or dependence on other drugs than are those born earlier.

\section{ACKNOWLEDGMENT}

The authors wish to thank the staff at UMARC for all of their efforts and anonymous reviewers for helpful comments. A portion of this paper was presented at the 1998 Annual Meeting of the Research Society on Alcoholism, June 20-25, 1998, Hilton Head, South Carolina.

\section{REFERENCES}

Berglund M (1988) Alcoholics committed to treatment: A prospective long-term study of behavioral characteristics, mortality, and social adjustment. Alcohol Clin Exp Res 12:19-24.

Boehnke M, Langefeld CD (1998) Genetic association mapping based on discordant sib pairs: The discordant-alleles test. Am J Hum Genet 62:950-961.

Buydens-Branchey L, Branchey MH, Noumair D (1989) Age of alcoholism onset: I. Relationship to psychopathology. Arch Gen Psych 46:225230.

Cloninger CR (1987) Neurogenetic adaptive mechanisms in alcoholism. Science (Wash. DC) 236:410-416.

Cloninger CR, Sigvardsson S, Bohman M (1996) Type I and Type II alcoholism: An update. Alcohol Health Res World 20:18-23.

Edenberg HJ, Reynolds J, Koller DL, Begleiter H, Bucholz KK, Conneally M, Crowe R, Goate A, Hesselbrock V, Li TK, Nurnberger JI, Porjesz B, Reich T, Rice JP, Schuckit M, Tischfield JA, Foroud T (1998) A family-based analysis of whether the functional promotor alleles of the serotonin transporter gene HTT affect risk for alcohol dependence. Alcohol Clin Exp Res 22:1080-1085.

Fillmore KM (1984) "When angels fall... ": Women's drinking as a cultural preoccupation and as reality, in Alcohol Problems in Women: Antecedents, Consequences, and Intervention (Wilsnack SC, Beckman LJ, eds), pp 7, Guilford Press, New York.

Fillmore KM (1987) Women's drinking across the adult life course as compared to men's. Br J Addict 82:801-811.

Gilligan SB, Reich T, Cloninger CR (1988) Alcohol-related symptoms in heterogeneous families of hospitalized alcoholics. Alcohol Clin Exp Res 12:671-678.

Glenn SW, Nixon SJ (1991) Applications of Cloninger's subtypes in a female alcoholic sample. Alcohol Clin Exp Res 15:851-857.

Grant BF (1997) Prevalence and correlates of alcohol use and DSM-IV alcohol dependence in the United States: Results of the National Longitudinal Alcohol Epidemiologic Survey. J Stud Alcohol 58:464473.

Gruber E, DiClemente RJ, Anderson MM, Lodico M (1996) Early drinking onset and its association with alcohol use and problem behavior in late adolescence. Prev Med 25:293-300.

Hill EM, Blow FC, Young JP, Singer KM (1994) Family history of alcoholism and childhood diversity: Joint effects on alcohol consumption and dependence. Alcohol Clin Exp Res 18:1083-1090.

Hill EM, Ross LT, Mudd SA, Blow FC (1997) Adulthood functioning: The joint effects of parental alcoholism, gender and childhood socioeconomic stress. Addiction 92:583-596.

Hill EM, Stoltenberg SF, Burmeister M, Closser M, Zucker RA (1999) Potential associations among genetic markers in the serotonergic system and the antisocial alcoholism subtype. Exp Clin Psychopharmacol 7:103-121.

Irwin M, Schuckit M, Smith TL (1990) Clinical importance of age at onset in type 1 and type 2 primary alcoholics. Arch Gen Psychiatry 47:320324.

Johnson RA, Gerstein DR, Ghadialy R, Choy W, Gfroerer J (1996) Trends in the Incidence of Drug Use in the United States, 1919-1992, DHHS Pub No (SMA) 96-3076. Substance Abuse and Mental Health Services Administration, Rockville, MD.

Labouvie E, Bates ME, Pandina RJ (1997) Age of first use: Its reliability and predictive utility. J Stud Alcohol 58:638-643.

Lander ES, Schork NJ (1994) Genetic dissection of complex traits. Science (Wash. DC) 265:2037-2048. 
Lappalainen J, Long JC, Eggert M, Ozaki N, Robin RW, Brown GL, Naukkarinen H, Virkkunen M, Linnoila M, Goldman D (1998) Linkage of antisocial alcoholism to the serotonin 5-HT1B receptor gene in 2 populations. Arch Gen Psychiatry 55:989-994.

Lewis CE, Smith E, Kercher C, Spitznagel E (1995) Assessing gender interactions in the prediction of mortality in alcoholic men and women: A 20-year follow-up study. Alcohol Clin Exp Res 19:1162-1172.

Lex BW, Sholar JW, Bower T, Mendelson JH (1991) Putative Type II alcoholism characteristics in female third DUI offenders in Massachusetts: A pilot study. Alcohol 8:283-287.

Mannuzza S, Fyer AJ, Endicott J, Klein DF (1985) Family Informant Schedule and Criteria (FISC). Anxiety Disorders Clinic, New York State Psychiatric Institute, New York.

McGue M, Pickens RW, Svikis DS (1992) Sex and age effects on the inheritance of alcohol problems: A twin study. J Abnorm Psychol 101: 3-17.

Midanik LT, Clark WB (1995) Drinking-related problems in the United States: Description and trends, 1984-1990. J Stud Alcohol 56:395-402.

National Institute of Alcohol Abuse and Alcoholism (1997) Epidemiology of alcohol use and alcohol-related consequences, in Ninth Special Report to the U.S. Congress on Alcohol and Health, p 1, NIH Pub No 97-4017.

Reich T, Cloninger CR, Van Eerdewegh P, Rice JP, Mullaney J (1988) Secular trends in the familial transmission of alcoholism. Alcohol Clin Exp Res 12:458-464.

Rice JP, Reich T, Buchoiz KK, Neuman RJ, Fishman R, Rochberg N, Hesselbrock VM, Nurnberger JI, Schuckit MA, Begleiter H (1995) Comparison of direct interview and family history diagnosis of alcohol dependence. Alcohol Clin Exp Res 19:1018-1023.

Risch N, Zhang $H$ (1995) Extreme discordant sib pairs for mapping quantitative trait loci in humans. Science (Wash. DC) 268:1584-1589.

Robins LN, Helzer JH, Croughan J, Williams JBW, Spitzer RL (1981) NIMH Diagnostic Interview Schedule: Version III. National Institute of Mental Health, Rockville, MD.
Schork NJ, Schork CM (1998) Issues and strategies in the genetic analysis of alcoholism and related addictive behaviors. Alcohol 16:71-83.

Schuckit, MA, Tipp JE, Smith, TL, Shapiro E, Hesselbrock VM, Bucholz KK, Reich T, Nurnberger Jl (1995) An evaluation of Type-A and Type-B alcoholics. Addiction 90:1189-1203.

Spielman RS, Ewens WJ (1998) A sibship test for linkage in the presence of association: The sib transmission/disequilibrium test. Am J Hum Genet 62:450-458.

Spielman RS, McGinnis RE, Ewens WJ (1993) Transmission test for linkage disequilibrium: The insulin gene region and insulin-dependent diabetes mellitus (IDDM). Am J Hum Genet 52:506-516.

Stevens G, Featherman DL (1981) A revised socioeconomic index of occupational status. Soc Sci Res 10:364-395.

Stoltenberg SF, Mudd SA, Blow FC, Hill EM (1998) Evaluating measures of family history of alcoholism: Density versus dichotomy. Addiction 93:1511-1520.

Terwilliger JD, Ott J (1992)A haplotype-based "haplotype relative risk" approach to detecting allelic associations. Hum Hered 42:337-346.

van den Bree M, Johnson EO, Neale MC, Svikis DS, McGue M, Pickens RW (1998) Genetic analysis of diagnostic systems of alcoholism in males. Biol Psychol 43:139-145.

Zucker RA (1994) Pathways to alcohol problems and alcoholism: A developmental account of the evidence for multiple alcoholisms and for contextual contributions to risk, in The Development of Alcohol Problems: Exploring the Biopsychosocial Matrix of Risk, NIAAA Research Monograph 26; NIH Pub No 94-3495 (Zucker R, Boyd G, Howard J eds), pp 255-289, Department of Health and Human Services, Rockville, MD.

Zucker RA, Ellis DA, Fitzgerald HE, Bingham CR, Sanford K (1996) Other evidence for at least two alcoholisms: II. Life course variation in antisociality and heterogeneity of alcoholic outcome. Dev Psychopathol $8: 831-848$. 